\title{
DIÁLOGO ENTRE H. P. LOVECRAFT E ARTHUR MACHEN: UMA ANÁLISE COMPARATIVA DE THE DUNWICH HORROR E THE GREAT GOD PAN
}

Shirley de Souza Gomes Carreira (UERJ)

Recebido em 04 mar 2017. Shirley de Souza Gomes Carreira possui Graduação em Aprovado em 30 mar 2017. Letras, Português-Inglês, pela Universidade Federal do Rio de Janeiro (1980), mestrado em Interdisciplinar Lingüística Aplicada pela Universidade Federal do Rio de Janeiro (1995), doutorado em Literatura Comparada (Ciência da Literatura) pela Universidade Federal do Rio de Janeiro (2000) e pós-doutorado em Literaturas de Língua Inglesa pela UERJ (2004-2005). É membro do Banco de Avaliadores do Sistema Nacional de Avaliação da Educação Superior/ BASis, INEP e do Banco de Consultores Ad Hoc da FUNADESP e da FAPERJ. Como ensaísta, tem trabalhos publicados em livros e periódicos do Brasil, México, Portugal, Estados Unidos e Inglaterra. Sua produção ensaística aborda os seguintes temas: pós-colonialismo, questões de identidade e de gênero, estudos culturais, diásporas, multiculturalismo e a produção textual dos escritores migrantes. Sua pesquisa atual focaliza as relações entre Literatura e Memória Étnica. Exerceu a função de professor adjunto-doutor I na Universidade do Grande Rio por 12 anos, onde também foi Coordenadora do Curso de Letras, Coordenadora do Curso de Especialização em Língua Inglesa, Coordenadora Pedagógica do Núcleo Multidisciplinar de Educação a Distância e Coordenadora do Programa de Mestrado 
em Letras e Ciências Humanas. É fundadora e faz parte do conselho editorial da Revista Eletrônica do Instituto de Humanidades da UNIGRANRIO. Atua também como investigadora convidada do Centro de Estudos Linguísticos, Comparados e Multimédia da Universidade Autónoma de Lisboa. Foi Coordenadora Institucional do Pibid UNIABEU, Coordenadora do Programa de Apoio à Pesquisa e Pró-Reitora Acadêmica da UNIABEU, onde também lecionou no Curso de Letras e exerceu a função de editoragerente dos periódicos UNIABEU e de editora-chefe da Revista e-scrita, do curso de Letras, e da Revista UNIABEU. Atualmente, é Professora Adjunta da UERJ (FFP) e integra o quadro permanente do Programa de Pós-Graduação (stricto sensu) em Letras e Linguística da UERJ. Publicações recentes: Memória e identidade: ensaio, Diásporas e deslocamentos: travessias críticas, Poéticas do contemporâneo e Memória, Identidade e Cultura: ensaios.

Resumo: Em seu ensaio sobre o horror sobrenatural na literatura, H. P. Lovecraft dedica parte de um capítulo à obra de Arthut Machen, por quem nutria admiração e a quem atribuía a capacidade de elaborar um "êxtase do medo" inalcançável aos outros escritores do gênero. The Great God Pan, primeira e mais conhecida obra de Machen, foi publicada no ano em que Lovecraft nasceu e este a menciona mais de uma vez em seus escritos, admitindo publicamente que ela o havia inspirado na escrita de alguns dos seus textos. Este trabalho propõe a análise do conto The Dunwich Horror, de Lovecraft, e da novela The Great God Pan, de Machen, a fim de verificar os pontos de convergência entre as obras.

Palavras-chave: Lovecraft; Machen; Weird fiction.

Abstract: In his essay on supernatural horror in literature, H. P. Lovecraft devotes part of a chapter to the work of Arthut Machen, whom he admired and to 
whom he attributed the ability to elaborate a "rapture of fear" unachievable to other writers of the genre. The Great God Pan, Machen's first and best-known work, was published in the year Lovecraft was born and he mentioned it more than once in his writings, publicly admitting that it had inspired him in writing some of his texts. This work proposes to analyze Lovecraft's short story The Dunwich horror and Machen's novella The Great God Pan, in order to verify the points of convergence between them.

Keywords: Lovecraft; Machen; Weird fiction.

\section{INTRODUÇÃO}

A emoção mais forte e mais antiga do homem é o medo, e a espécie mais forte e mais antiga de medo é o medo do desconhecido. (H.P. LOVECRAFT)

A Howard Phillips Lovecraft atribui-se uma revolução do gênero de horror, pois a ele se deve a inserção de novos elementos e o conceito de "Horror Cósmico", que ele elaborou para expor suas formulações teóricas sobre a narrativa de horror e determinar um padrão para os textos que desejava produzir.

Segundo Remo Ceserani (Apud DUTRA, 2015, p.58), os estudos teóricos visando a definir o que seria literatura fantástica seguem duas vertentes principais: a que a identifica somente com um gênero literário historicamente limitado a alguns textos e escritores do século XIX e a que a estende sem limites históricos a todo um setor da produção literária, no qual coexistem outros modos, formas e gêneros, do romanesco ao fabuloso, da fantasy à ficção científica, do romance àquele de terror, do gótico ao 
oculto, do apocalíptico ao metarromance contemporâneo. Esta última tem sido a de uso mais corrente, fazendo com que a literatura fantástica tenha o escopo de um umbrella term, abrangendo os gêneros ficção científica, horror e fantasia, ou seja, uma variedade de textos literários que partilham em comum apenas a característica de ser um contraponto à literatura de cunho realista.

Entretanto, a produção literária de Lovecraft assume um caráter distinto de cada um desses gêneros. Em suas cartas, Lovecraft referiase a si mesmo como um autor de weird fiction 1 , termo que tomou por empréstimo do autor irlandês Sheridan Le Fanu e popularizou em seu ensaio sobre o horror sobrenatural na literatura.

Segundo Lovecraft (1973), weird fiction caracteriza um tipo de ficção que contém elementos sobrenaturais, mas não pode ser classificada como uma história de fantasma tradicional ou como uma narrativa gótica. Segundo Dutra (2015, p.60), "a weird fiction seria, grosso modo, um gênero cuja meta é criar uma atmosfera, seja esta onírica, de horror ou estranhamento, ou, em outros termos, uma atmosfera que faça o leitor sentir-se fora da realidade empírica".

Pode-se então afirmar que a principal condição para a existência da weird fiction é a capacidade de provocar no leitor um "sentimento de apreensão, e de contato com esferas diferentes e forças desconhecidas" (LOVECRAFT, 1973, p.5). Para Lovecraft, uma boa história de horror deve estar centrada não no fator que provoca o horror, mas no modo como ele é revelado ao leitor.

1 Adotaremos neste artigo a tradução "ficção do estranho", por considerarmos que é a que mais se aproxima do sentido em inglês. 
A escrita ficcional de Lovecraft pode ser dividida em dois grupos: a fase dunsaniana e os mitos Cthulhu. O primeiro se reporta a uma série de textos produzidos por Lovecraft de 1919 a 1921, inspirados pelo escritor irlandês Lord Dunsany. Os textos desse grupo apresentam em comum uma localização indeterminada, numa atmosfera onírica e exótica. O segundo, assim denominado por Auguste Derleth, designa um panteão de criaturas imaginárias que habitam o universo ficcional de Lovecraft e que foi expandido posteriormente por seus seguidores.

Em "O horror sobrenatural na literatura", Lovecraft faz uma retrospectiva de obras em que o horror e o fantástico estão presentes e, em um capítulo dedicado aos mestres modernos, ele faz referência a Arthur Machen, cujos textos veio a conhecer em 1923:

Dos criadores vivos do pavor cósmico elevado ao seu mais alto expoente artístico, dificilmente poderá citar-se algum que se iguale ao versátil Arthur Machen, autor de cerca de uma dúzia de composições longas e curtas em que os elementos de horror oculto e medo avassalante atingem uma substância e um realismo quase incomparáveis. $(1973$, p.86)

Este artigo propõe a análise comparativa de duas narrativas, a história curta The Dunwich horror, de Lovecraft, e a novela The Great God Pan, de Arthur Machen, de modo a identificar pontos de convergência entre elas.

\section{A CONCEPÇÃO LOVECRAFTIANA DO HORROR CÓSMICO}

Lovecraft teve contato com a literatura de grandes escritores já na infância e na adolescência, pois a biblioteca do seu avô era 
ampla e continha obras do século XVIII, e o acesso à pulp fiction ${ }^{2}$, possibilitou a ampliação do seu conhecimento, que passara a englobar histórias de aventura, horror, western, suspense, histórias de amor, e outros gêneros voltados ao gosto popular. Leitor ávido, Lovecraft encontrou em Poe, cuja obra leu aos oito anos de idade, fonte de inspiração para os seus primeiros escritos. O contato com obras de outros autores, como Ambrose Bierce, Lord Dunsany, Arthur Machen, Algernon Blackwood, M. R. James e Robert W. Chambers, com certeza o ajudaram a definir o tipo de ficção que desejava escrever. Ao combinar ficção científica com horror, criou seu próprio gênero literário, o "horror cósmico", ou seja, conforme afirma Dutra, transformou o horror tradicional, de origem sobrenatural, em um horror de origem científica.

O papel do leitor é crucial na concretização do texto, pois a ele cabe reconhecer na narrativa algo aparentemente impossível de existir e que, apesar dessa impossibilidade e do perigo que a sua existência representa no universo ficcional em que as personagens transitam, captura a sua atenção, replicando no mundo extradiegético sensações que as personagens têm no mundo intradiegético.

Outro aspecto relevante é o fato de que, ao contrário do que ocorre na ficção científica, as personagens de Lovecraft não buscam contato com criaturas ontologicamente diferentes, mas receiamnas e se sentem impotentes diante de forças desconhecidas.

2 Ficção publicada em revistas impressas em papel barato de consumo e temática popular como a fantasia e a ficção científica. 


\section{NARRATIVAS DE LOVECRAFT E MACHEN: PONTOS DE CONVERGÊNCIA}

The Dunwich horror ${ }^{3}$ é o único texto ficcional de Lovecraft que menciona explicitamente a obra de Machen, muito embora não tenha sido o único a estabelecer diálogos com ela. É uma história curta que faz parte do grupo de narrativas denominado "mitos Cthulhu" e gira em torno da relação de uma família, os Whateleys, com terríveis acontecimentos ocorridos em Massachusetts, em 1928, que passaram a ser referidos como "o horror de Dunwich".

Ao situar geograficamente a história, o narrador se reporta a lendas relacionadas a ritos profanos, nos quais eram invocadas formas proibidas de sombra que saiam das colinas e eram feitas preces orgiásticas respondidas por crepitações e estrondos vindo do chão. Relembra ainda as tradições que falavam de odores fétidos perto dos círculos de pedras nas colinas e de presenças etéreas, bem como de certa quantidade de ossos encontrados dentro dos círculos e em torno de uma pedra em forma de mesa na Colina Sentinela. Mesmo afirmando que eram crendices, ele passa a relatar a história da família Whateley.

Os três membros da família, o velho Whateley, sua filha Lavínia e o neto Wilbur são descritos como indivíduos que causam estranhamento na comunidade local. O velho por ser considerado um bruxo; a filha, pela aparência, devido ao fato de ser albina; e o neto por sua compleição física e crescimento incompatível com a idade. A natureza insólita do menino é preconizada pelos estranhos ruídos ouvidos na noite anterior ao seu nascimento e confirmada 3 As citações da obra em língua portuguesa foram traduzidas por Lara D’Onofrio Longo. 
em sua aparência: "uma criança escura e semelhante a um bode", que contrastava com o albinismo da mãe.

Ante as especulações dos vizinhos acerca da paternidade da criança, o velho Whateley afirma que um dia eles ouvirão Wilbur chamar o nome do seu pai desconhecido no alto da Colina Sentinela.

O crescimento anormal da criança é tão notável quanto a sua aparência:

Embora compartilhasse a falta de queixo de sua mãe e de seu avô, seu nariz firme e precoce, aliado à expressão de seus grandes olhos escuros, quase latinos, davam-Ihe um certo ar de adulto e uma inteligência incomum. Ele era, no entanto, extremamente feio apesar de sua aparência brilhante; havia algo quase caprino ou animalesco em seus lábios grossos, na pele amarelada e de poro grandes, nos cabelos crespos e grossos e nas orelhas estranhamente alongadas. (LOVECRAFT, $s / n$ )

Dois fatos despertam a atenção da vizinhança. O primeiro deles é que, desde o nascimento de Wilbur, o velho Whateley comprava gado frequentemente, sem que nenhum acréscimo fosse verificável em seu rebanho, permanentemente esquálido, maltratado e coberto de estranhas feridas, verificáveis também em Whateley e Lavínia. O segundo, a reforma esquisita que o velho realizava na casa. Ele havia fechado com madeira todas as janelas do segundo andar, que não mais era acessível por dentro, mas tinha uma rampa externamente, que partia de uma janela transformada em porta e dava acesso à colina.

As habilidades e o crescimento descontrolado de Wilbur passam a ser alvo do interesse da população local, assim como o 
seu possível envolvimento no desaparecimento de algumas jovens da localidade.

Whateley, considerado bruxo e louco, iniciara o jovem na leitura de livros proibidos e quando está prestes a morrer o encarrega de cuidar de algo, a que denomina Yog-Sothoth, para quem deve abrir determinados portões, por meio de uma reza que está na página 751 de um livro, intitulado Necronomicon.

O mais famoso dos livros fictícios criados por Lovecraft é um grimório, onde são descritos rituais para ressuscitar os mortos, para contatar entidades sobrenaturais, viajar para outras dimensões e também trazer de volta à Terra divindades que haviam sido banidas e aprisionadas. O poder do grimório faz com que sua leitura seja suficiente para provocar a loucura e a morte.

Depois da morte do Velho Whateley, Lavínia desaparece misteriosamente. Não sem antes comentar com uma vizinha que sentia medo do filho.

Para cumprir a promessa feita ao avô, Wilbur vai até a universidade de Miskatonic, onde, finalmente, encontra o livro. Só então o leitor toma ciência de que o avô de Wilbur havia lhe dado um exemplar defeituoso, em que uma importante passagem havia se tornado ilegível, razão pela qual necessitava cotejar os dois textos. A informação de que necessita, um encantamento contendo o nome Yog-Shototh, é encontrada. A página do livro contém referências a um portal a ser transposto pelos "Antigos", criaturas que concretizariam a ameaça de destruição da humanidade. $\mathrm{O}$ guardião desse portal é Yog-Sothoth, senhor do tempo. Segundo o texto, os antigos, invisíveis ao homem, reconhecíveis apenas 
pelo seu odor fétido, geraram seres híbridos, que vivem na Terra. O bibliotecário, Dr. Armitage, que acidentalmente lê o texto, sente uma onda de temor ao fazê-lo e nega a Wilbur o direito de levar consigo o livro como empréstimo.

A história prossegue com as inquietações do Dr. Armitage e culmina na tentativa de Wilbur de roubar o Necronomicon. Despertado pelos latidos do cão de guarda do campus e em meio a um horrível mau cheiro, ele se dirige à sala de leitura genealógica onde o exemplar está e depara com uma criatura de quase três metros de altura, com o corpo dilacerado pelas mordidas do cão.

Era parcialmente humano, sem sombra de dúvida, com mãos e cabeça muito semelhantes a homens, e o rosto caprino, sem queixo, tinha o carimbo dos Whateleys sobre ele. Mas o tronco e as partes inferiores do corpo eram teratologicamente fabulosos, de modo que somente roupas generosas podiam ter permitido que ela caminhasse na terra sem ser desafiada ou não.

Acima da cintura era semiantropomórfica; Embora seu peito, onde as patas rasgadas do cão ainda descansavam com vigilância, tinha a pele reticulada e coriácea de um crocodilo ou jacaré. As costas eram malhadas de amarelo e preto e tinham semelhança com a cobertura escamosa de certas cobras. Abaixo da cintura, porém, era muito pior; porque aqui toda a semelhança humana desaparecia e começava. A pele era coberta por uma camada grossa de pelos negros e ásperos, e uma fileira de tentáculos longos cinza- esverdeados com ventosas vermelhas projetavam-se molemente do abdome. [...] Em cada um dos quadris, profundamente situado em uma espécie de órbita rosada, ciliada, encontrava-se o que parecia ser um olho rudimentar; enquanto que 
em vez de uma cauda, dependia de uma espécie de tronco ou palpo com marcas anulares roxas, e com muitas evidências de ser uma boca ou garganta subdesenvolvida. Os membros, com exceção de sua pelagem negra, lembravam grosseiramente as patas traseiras dos sauros gigantes da Terra pré-histórica; e terminavam em hipotênares que não eram cascos nem garras. Quando a coisa respirava, sua cauda e tentáculos mudavam de cor ritmicamente, como se obedecendo a alguma causa circulatória normal para o lado não humano de sua ascendência. Nos tentáculos, isso era observável como um aprofundamento da coloração esverdeada, enquanto na cauda se manifestava como uma aparência amarelada que alternava com um branco-acinzentado doentio nos espaços entre os anéis roxos. De sangue genuíno, não havia nada; apenas o licor amareloesverdeado e fétido que gotejava ao longo do chão pintado para além do alcance daquela viscosidade, e deixava uma descoloração curiosa por onde passava. (LOVECRAFT, s/n)

Armitage identifica Wilbur de imediato e é testemunha de um incrível processo de desintegração:

Entretanto, estavam ocorrendo mudanças assustadoras no chão. Não é necessário descrever o tipo de encolhimento e desintegração que ocorria diante dos olhos do Dr. Armitage e do Professor Rice; mas é admissível dizer que, além da aparência externa do rosto e das mãos, o elemento realmente humano em Wilbur Whateley deve ter sido muito pequeno. Quando o médico legista chegou, havia apenas uma massa pegajosa e esbranquiçada nas tábuas pintadas, e o odor medonho quase desaparecera. Aparentemente Whateley não tinha crânio ou esqueleto ósseo; pelo 
menos, em qualquer sentido verdadeiro ou estável. Tinha tomado um pouco de seu pai desconhecido. (LOVECRAFT, s/n)

Pouco tempo depois, uma outra criatura escapa da casa dos Whateley, causando uma devastação. Aparentemente abandonada após a morte de Wilbur, ela vaga pelas redondezas destruindo casas e consumindo rebanhos. Invisível aos olhos humanos, causa grande temor na população, que pode apenas ver os seus rastros e sentir seu odor fétido.

O horror de Dunwich termina graças à intervenção de Armitage, que, assombrado pelas anotações de Wilbur em um diário, se dirige à localidade com dois amigos. Ante a impossibilidade de ver contra o que está lutando, decide pulverizar a criatura com um pó, de modo que as suas formas sejam reveladas. Por meio de um encantamento proferido na Colina Sentinela, ele faz a criatura desaparecer; não antes de ouvi-la invocar Yog-Sothoth, em inglês, pedindo a sua ajuda e chamando-o de pai. Por fim, Armitage revela a verdadeira natureza do monstro:

No que se refere a essa criatura que acabamos de mandar de volta, os Whateley a criaram para desempenhar um papel terrível nos feitos que estavam por vir. Cresceu rápido e ficou grande pelo mesmo motivo que Wilbur cresceu rápido e ficou grande, mas o superou porque tinha uma porção maior de exterioridade nele. [...] Era seu irmão gêmeo, mas se parecia mais com o pai do que ele. (LOVECRAFT, s/n)

Todas as modificações feitas na casa dos Whateley visavam a acomodar a criatura em seu crescimento descontrolado. 
Com o desfecho, o leitor compreende que as feridas nos animais e nos membros da família Whateley eram causadas pelas ventosas daquele ser monstruoso, que se alimentava do gado comprado pelo velho Whateley. Depreende também que as jovens desaparecidas foram sacrificadas nos cultos a Yog-Sothoth realizados na Colina Sentinela.

Conforme Bezarias (2006) enfatiza, nos mitos Cthulhu criados por Lovecraft, Yog-Sothoth é uma das seis potestades abomináveis que intervêm na Terra, segundo um plano que consiste na destruição da humanidade.

O elo entre The Dunwich horror e a novela de Machen consiste em uma alusão feita por Armitage após a visita de Wilbur à universidade de Miskatonic: "- Endogamia? - Armitage pronunciou meio alto para si -. Deus meu, que simplórios! Mostre a eles o grande deus Pã de Arthur Machen e vão pensar que é um escândalo corriqueiro como os de Dunwich".

The Great God Pan foi primeiramente publicada no periódico The Whirlwind, em 1890. Ao longo do tempo inspirou diversos autores, não apenas Lovecraft, mas também autores contemporâneos, como Stephen King, que, em uma autoentrevista postada em seu site oficial, atribui a ela a inspiração para a novela N., publicada na coletânea Just after sunset (2008).

A novela de Machen foi produzida em uma época em que predominava o que Todorov chamou de "romance negro", ou seja, universos ficcionais permeados de acontecimentos insólitos, visões fantasmagóricas, seres macabros e locais lúgubres, que têm em The Castle of Otranto (1764), de Horace Walpole, o seu 
primeiro exemplar, segundo a tradição. Entretanto, The Great God Pan distancia-se do modelo gótico introduzindo novas abordagens do insólito na ficção, principalmente pautadas na crença do autor de que o mundo ordinário oculta um mundo paralelo, vedado ao homem.

Segundo Carreira (2017, p.92),

Ao contextualizar a história na Inglaterra do século XIX, Machen rompe com os cenários tradicionais da literatura gótica, porém faz com que pulsões ocultas que habitam o imaginário humano coexistam com a ambientação e o puritanismo vitorianos.

Em The Great God Pan, como o título sugere, há a incorporação do mito de Pã na narrativa. Na mitologia grega, Pã era uma divindade com chifres e pernas de bode, que vivia nos bosques e era temida por aqueles que os atravessam à noite.

Estudos da biografia de Machen comprovam que, desde cedo, ele apresentou certo misticismo, que colaborou para o desenvolvimento de sua abordagem peculiar da literatura de horror e à incorporação aos seus textos de elementos tais como o povo pequeno, raça humanoide aborígene que, segundo a tradição, teria habitado as Ilhas Britânicas, além de mitos gregos e romanos.

A novela, dividida em cinco capítulos, inicia com uma experiência realizada por um neurologista, na presença de seu amigo Clarke. O Dr. Raymond acredita que por meio da manipulação do cérebro de sua criada Mary, ela será capaz de vislumbrar um mundo espiritual, por ele denominado "a visão do Grande Pã". O que Raymond pretende de fato é abrir um canal de comunicação com um outro plano, governado por seres míticos. 
Pode-se observar já nessa proposta inicial um ponto de contato com The Dunwich horror, pois as duas obras compartilham a ideia de que é possível a comunicação entre dimensões, bem como a liberação de uma força desconhecida através desses portais.

Em The Great God Pan, o resultado da experiência é inesperado, pois ao invés de adentrar um mundo de conhecimento, "a jovem acorda da breve cirurgia com estertores de pavor, como se tivesse experimentado o maior horror que alguém já pudesse ter sentido, tornando-se, desde então, mentalmente doente" (CARREIRA, 2017, p.92).

De repente se ergueu o som dum suspiro, o sangue voltou a corar o rosto exangue de Maria, os olhos se abriram e brilharam com estranho fulgor. Uma grande admiração se espelhou na face e as mãos se estenderam como pra tocar algo invisível. E logo o espanto se converteu em horror, o rosto numa máscara abominável, e o corpo começou a tremer de tal forma que, se diria, era sua alma lutando na prisão carnal. Horrível visão! Clarke se precipitou porta afora, enquanto a jovem caía ao chão, uivando. (MACHEN, 1986, p.8)

Na narrativa de Lovecraft, há uma situação similar, pois a personagem a quem cabe promover a abertura do portal, Wilbur Whateley, morre sem ter conseguido levar a cabo o seu intento. Há, no entanto, que enfatizar que o insucesso da cirurgia na novela de Machen resulta do descrédito do autor em relação à ciência.

Os capítulos em The Great God Pan aparentam não ter conexão entre si, pois há cortes súbitos, como o que ocorre do primeiro para o segundo capítulos. Após o relato da cirurgia, há um salto na narrativa e o cenário passa a ser Londres, onde Clarke, 
que tenta compilar um livro intitulado Memórias para provar a existência do diabo, lê a narrativa de um amigo, Dr. Phillips, sobre estranhos acontecimentos ligados a uma moça galesa, Helen Vaughan. Ao leitor é revelado apenas o fato de que a moça fora adotada e que tinha estranhos hábitos, como o de embrenhar-se na floresta horas a fio.

Dois acontecimentos inusitados são associados à presença de Helen: a loucura que acomete o menino Trevor, que, após tê-la visto com um homenzinho na floresta, tem o seu comportamento alterado, tornando-se completamente insano quando reconhece a fisionomia do tal homem na estátua de um fauno; bem como o desaparecimento súbito da jovem Rachel - que costumava passear com Helen -, depois fazer revelações aterradoras à mãe.

Um aspecto preponderante na narrativa de Machen consiste na omissão de dados, deixando ao leitor a tarefa de conjeturar o desenrolar dos acontecimentos, como é possível observar na passagem a seguir:

Numa noite, contudo, depois de Raquel voltar, a mãe ouviu no quarto algo que Ihe pareceu um choro abafado. Entrou e encontrou a filha meio despida, sentada na cama, tomada de indizível angústia. Ao ver a mãe, gritou: Ó! Mamã! Por que me deixaste ir com Helena à floresta? Espantada em ver a filha naquele estado, senhora M... a interrogou e Raquel contou uma história terrível. Disse... (MACHEN, $1894, s / n)$

O leitor não tem acesso ao teor dessa revelação, cabendo-lhe apenas deduzir sua gravidade a partir do efeito que ela provoca em Clarke: 
- Meu Deus! Pensa no que dizes! É monstruoso! Coisas como essa nesta nossa terra, onde o homem vive e morre, luta, triunfa, às vezes sucumbe, é vencido pela tristeza e sofre, vítima de estranhos destinos ao longo de vários anos, bem sei! ... Mas isso, Philips, isso não! Se isso pudesse acontecer, este mundo seria um pesadelo! (MACHEN, 1894, s/n)

A incapacidade de narrar o insólito, presente no texto de Machen, parece ter inspirado Lovecraft de algum modo, pois, ao longo de sua obra, este adota a estratégia de descrever objetos por meio de alusões, como a demonstrar que o insólito não pode ser nomeado. Em Weird Fiction, Graham Harman (2012) afirma que o conceito de lacuna é essencial para a compreensão da obra de Lovecraft, pois nenhum autor reflete com tanta propriedade a perplexidade ante a insuficiência da linguagem para descrever os objetos.

Ainda sobre as omissões em The Great God Pan, Carreira afirma que

uma característica marcante da obra é o fato de que o insólito não é introduzido por meio de ações, mas de um conjunto de relatos, interrompidos justamente nas partes em que os fatos geradores do medo deveriam ser expostos. Essa técnica parece fazer parte de um jogo narrativo de exposição e ocultamento que se estende por todo o texto, concretizando no âmbito da arquitetura do texto o tema que a narrativa explora. (CARREIRA, 2017, p.94)

O terceiro capítulo traz à cena uma nova personagem, Villiers, que encontra, ao acaso, um velho amigo, Charles Herbert, em decadência física e moral, causada pela esposa, Helen, que, em suas palavras, "o corrompera de corpo e alma" e, em seguida, desaparecera. 
No capítulo seguinte, Villiers relata essas circunstâncias a Clarke, que, ao ver um retrato da esposa de Herbert, desconfia de que há uma ligação entre ela e os acontecimentos ocorridos em Gales. Surpreendentemente, reconhece nela os traços de Mary, a infortunada jovem que fora operada pelo Dr. Raymond.

A arquitetura do medo em $O$ grande deus $P \tilde{a}$ é construída paulatinamente, pois, à medida que a narração evolui, o leitor é levado a crer que acontecimentos terríveis são associados à Helen Vaughan e a reação das demais personagens cria um clima crescente de terror. O texto de Machen desperta no leitor empírico a curiosidade sobre os eventos que causam tamanho horror nas personagens. No entanto, eles não são revelados e cabe ao leitor conjeturá-los a partir dos indícios textuais.

A onda de suicídios que ocorre na cidade é o foco do capítulo cinco. Todos os suicidas são cavalheiros ricos de Londres e tiveram algum tipo de relacionamento com uma certa Sra. Beaumont, que chegara recentemente da América. Cabe a Villiers desvendar o mistério. Investigando o paradeiro de Helen, ele descobre que ela e a Sra. Beaumont são a mesma pessoa e que, de algum modo, ela persuadia os homens a ações que os levavam à loucura e à morte.

Helen emblematiza a violação de leis humanas e naturais. A figura arquetípica de Pã, a que ela está associada, relaciona os fatos geradores do medo a uma atividade sexual transgressora:

Olha este belo manuscrito. Foi paginado. Estás vendo? E levei a galanteria a ponto de o atar com fita vermelha. Parecem papéis de negócio. Não parecem? Veja-os bem, Austin. Neles está a descrição das distrações que senhora Beaumont oferecia a seus hóspedes de eleição. O homem 
que escreveu isso conseguiu escapar vivo, mas não creio que durante muito tempo. Os médicos acham que deve ter tido um grande abalo.

Austin pegou o manuscrito, mas não o leu. Abrindo ao acaso a vista caiu sobre uma palavra, o princípio duma frase, e, com o coração saltando, os lábios brancos e a testa suada, atirou o papel ao chão.

- Toma-o, Villiers, e não me fale mais disso. Raios, homem! És de pedra? Diabos! Mesmo o medo e o horror à morte ou o pensamento dum homem que será enforcado, no momento em que ouve as sinetas tocando e fica esperando o ruído do patíbulo, nada é comparado a isso. Não quero ler, pois nunca mais conseguiria dormir. (MACHEN, 1986, p.41)

A força mítica de Pã é invocada na réplica de Villiers ao horror que o manuscrito despertara em Austin:

- Está bem! Imagino o que leste e sei quão horrível é. Mas, apesar de tudo, é uma velha história, um mistério antigo recuperado em nossa época, com as ruas de Londres substituindo os antigos vinhedos e olivais. Sabemos o que acontecia a quem encontrasse o deus Pã. Os sábios acham que todo símbolo o é duma realidade e não do nada. E era, na verdade, um símbolo bem refinado, esse, sob o qual os antigos velavam as forças secretas e terríveis que se escondem no coração de todas as coisas, perante as quais a alma humana se desvanece e morre, enegrecida, como o corpo ficaria se atacado por correntes elétricas. Essas forças só podem ser nomeadas e concebidas através dum véu que para a maioria não mais é que uma fantasia poética e pra alguns uma história contada por idiotas e loucos. Mas nós, tu e eu, conhecemos um pouco do terror 
que pode habitar os reinos secretos da vida, sob a aparência da carne. Vimos o informe assumir uma forma. (MACHEN, 1986, p.41)

Quando Villiers decide confrontar Helen, ela é persuadida a enforcar-se com uma corda que ele Ihe entrega. Sua morte ocorre de modo inusitado, pois seu corpo sofre mutações sucessivas, de um gênero a outro e de humana à besta, dissolvendo-se e reconstituindo-se, até extinguir-se por completo.

No último capítulo, intitulado "Fragmentos", essa metamorfose é descrita pelo médico que fizera a autópsia:

Se bem que atacado por uma náusea de revolta e quase sufocado pelo odor da corrupção, me mantive firme, privilegiado ou maldito, não sei, olhando o que ali estava, negro como tinta, e que se transformava perante meus olhos. Pele, carne, músculo e osso, e a firme estrutura do corpo humano, tudo o que, até então, considerara algo permanente como o diamante, começou a se fundir e dissolver. Sabia que agentes exteriores podiam assim devolver o corpo aos elementos mas me recusaria a crer naquilo que via porque havia ali uma força interna que eu não conhecia e que ordenara a dissolução e a metamorfose. Ali se repetiu, em minha frente, todo o esforço que originou o homem. Vi a coisa vacilar de sexo a sexo, se dividir e se unificar de novo. Vi o corpo regredir às feras que o precederam, o que estava na coroa dos seres descer ao inframundo, ao abismo. Mas o princípio da vida, que cria o organismo, permanecia estável no meio das transformações da forma [...] Eu olhava sempre: Logo nada mais restava além duma substância semelhante a gelatina. $E$ depois a escala foi de novo percorrida, em sentido inverso... (neste ponto são ilegíveis algumas linhas 
do manuscrito)... instante vi uma forma obscura à minha frente, que não quero descrever. Mas o símbolo pode ser encontrado nalgumas estátuas antigas e naquelas pinturas que sobreviveram à lava, demasiado infames pra que eu fale mais sobre elas... E a indizível aparência, homem e besta, retomou a forma humana. Então a morte sobreveio. (MACHEN, 1894, s/n)

Em The Dunwich horrors, tanto Wilbur quanto o seu gêmeo alienígena passam por um processo de mutação, desintegrando-se. O diálogo com o texto de Machen é evidente.

The Great God Pan tem o mérito de inaugurar um tipo de narrativa de horror que transfere para o leitor "a tarefa de concretizar o elemento causador do medo" (CARREIRA, 2017, p.95). Longe de ser provocado por descrições assustadoras, o medo assume a forma do indizível, do inenarrável. Essa qualidade é reconhecida por Lovecraft, que afirma: "Há em Machen um êxtase do medo [grifo nosso] que todos os outros homens são demasiadamente obtusos ou tímidos para capturar, e mesmo Poe não conseguiu prever em toda a sua contundente anormalidade" ${ }^{\prime 4}$.

Arthur Machen tinha um fascínio pelo ocultismo e pelo paganismo, que influenciaram as suas primeiras obras. Fez parte, durante algum tempo, da famosa ordem mística Golden Dawn (Aurora Dourada), onde teve confrades de todos os tipos, desde os mais ilustres, como o poeta W. B. Yeats, até os menos recomendáveis, como o notório satanista e praticante de magia negra Aleister Crowley. Lovecraft, por sua vez, usou as mitologias suméria, egípcia e grega como base para os seus semideuses monstruosos. Não há

4 In: http://www.victoriangothic.org/arthur-machen-an-ecstasy-of-fear/\#more-332 Acesso em 03.Jul.2016. 
como deixar de observar que assim como a estátua de Pã causa um grande impacto no menino Trevor em The Great God Pan, ao ponto de levá-lo à insanidade, em "The call of Cthulhu", a narrativa de Lovecraft que dá origem aos mitos Cthulhu, é também a estátua de um ser híbrido que desencadeia a história.

Digna de nota é a afirmação de S. T. Joshi e Kenneth Hite (2008) de que The Dunwich horror, como outras histórias tardias de Lovecraft, foge do esquema de indiferença cósmica que caracterizou sua ficção, pendendo para um embate entre o bem e o mal, que se mostra igualmente evidente em The Great God Pan. Para Joshi e Hite, muito embora tentasse escrever ficção em consonância com a sua teorização, nem sempre o autor foi bem sucedido.

\section{CONSIDERAÇÕES FINAIS}

Esta breve análise de The Dunwich horrors e The Great God Pan demonstra pontos de convergência que já haviam sido, de certo modo, preconizados quando Lovecraft inseriu em seu texto a alusão à novela de Machen.

O cenário agreste e misterioso de The Dunwich horror encontra eco, por exemplo, nas paisagens do País de Gales, onde Helen Vaughan se encontra com estranhas criaturas. Nesses cenários são realizados ritos profanos e pode-se dizer que, de certa forma, o sacrifício das jovens no texto de Lovecraft se equipara aos suicídios da novela de Machen, pois ambos fazem parte do culto a divindades.

Wilbur e seu gêmeo são seres híbridos, filhos de uma entidade cuja origem é anterior à história humana, assim como Helen, e, como ela, passam por um processo de desintegração. Se o 
hibridismo em The Dunwich horror parece corresponder a uma necessidade dos Antigos de estabelecer uma forma mais estável da matéria em um novo espaço-tempo, em The Great God Pan, ele é o veículo para a inserção do mal em uma sociedade submetida a um severo controle moral.

Wilbur e Helen são, cada um a seu modo, transgressores. O primeiro por sua sede de conhecimento ser incompatível com a classe social a que pertence e superar a natureza humana. A segunda por assumir o papel de uma dominatrix demoníaca em um universo ficcional masculino. Assim, embora a transgressão esteja presente nas duas obras, em cada uma há uma motivação diferente.

Também é digna de nota a equivalência de papéis entre o Dr. Armitage e Villiers, uma vez que a eles cabe desvendar os mistérios que envolvem, respectivamente, o horror de Dunwich e os suicídios em série.

Para finalizar, há que mencionar o fato de que, nas duas obras, o acesso aos portais para outras dimensões é confiado a entidades míticas. Em The Dunwich horror, Yog-Sothoth, a deidade capaz de abrir o portal e permitir a entrada dos Antigos, é uma das entidades mais importantes e poderosas do panteão Lovecraftiano, pois sua posição hierárquica é inferior somente a de Azathoth, o líder dos Antigos. O escopo do seu poder deriva do seu controle sobre o tempo e o espaço. Lovecraft cria uma realidade fantástica, de caráter mitológico, que explica a origem do cosmos em um tempo anterior á existência humana. Em The Great God Pan, Pã tem uma natureza ctônica. Sua aparência híbrida, que se reporta a um cosmos dividido, é demonizada e associada a práticas sexuais abominadas 
pela sociedade vitoriana. Seu modus operandi é contrário ao de Yog-Sothoth. Ao invés de causar destruição no mundo onde as personagens transitam, ele subjuga a mente e a vontade humanas. É por meio dele que o mal ctônico adentra o universo ficcional.

Tanto em The Dunwich horror quanto em The Great God Pan os filhos dessas entidades são derrotados após um embate com os homens. Final controverso, segundo alguns críticos, mas em consonância com o modo como o homem lida com o desconhecido e com o medo da degeneração da raça humana.

\section{REFERÊNCIAS}

BEZÁRIAS, Carlos Alexandre (2006). "Funções do mito na obra de Howard Phillips Lovecraft". Dissertação de Mestrado (129 fl.). Universidade de São Paulo. In www.teses.usp.br/teses/disponiveis/8/.../TESE_CAIO_ALEXANDRE_BEZARIAS. pdf Acesso em 26.Fev.2017.

CARREIRA, Shirley S. G. (2017). "Entre humanos e bestas: o insólito ficcional em The Great God Pan e Shame". Ilha do Desterro [online]. Vol.70, n.1, p.91-101. In http:// www.scielo.br/scielo.php?script=sci_arttext\&pid=S2175-80262017000100091\& Ing=en\&nrm=isso. Acesso em 27.Fev.2017.

CESERANI, Remo (2006). O Fantástico. Londrina: Editora UFPR.

DUTRA, Daniel I. (2015). “O horror sobrenatural de H. P. Lovecraft: teoria e praxe estética do horror cósmico". Tese de Doutorado em Literatura comparada (263 fl.). Universidade Federal do Rio Grande do Sul. In http://www.lume.ufrgs.br/ handle/10183/128999. Acesso em 25. Fev.2017.

HITE, Kenneth (2008). Tour de Lovecraft. Alexandria: Atomic Overmind Press. JOSHI, S.T. (2008). The Weird Tale. New Jersey: Wildside Press.

(2007). Icons of Horror and the Supernatural. Westport, Connecticut, London: Greenwood Press.

LOVECRAFT, Howard Phillips (2008). O horror sobrenatural em literatura. Celso Mauro Paciornik (Trad.). São Paulo: Iluminuras. 
(S/D). O horror de Dunwich. Tradução de Lara D'Onofrio Longo. In www. thuleitalia.net/letteraria/Libri/.../H\%20P\%20Lovecraft\%20-\%20dunwich.pdf. Acesso em 24 de Fev.2017.

(S/D). The Dunwich horror. In http://www.hplovecraft.com/writings/ texts/fiction/dh.aspx. Acesso em 23 de Fev.2017.

MACHEN, Arthur (1894). The Great God Pan. The Project Gutenberg EBook. In https:// www.gutenberg.org/files/389/389-h/389-h.htm. Acesso em 20 de Jun.2016. 


\section{SUBLIME AND GROTESQUE: THE AESTHETIC DEVELOPMENT OF WEIRD FICTION IN THE WORK OF H. P. LOVECRAFT AND CHINA MIÉVILLE}

Linda Wight (FedUni)

Nicole Gadd (FedUni)

Recebido em $17 \mathrm{fev}$ 2017. Linda Wight is a Senior Lecturer in Literature and Aprovadoem 30 mar 2017. Screen Studies at Federation University Australia. Her primary research focuses on how men and masculinities have been depicted in science fiction, fantasy and other popular genres.

Nicole Gadd is a graduate of Federation University Australia. Her honours thesis, "Tracing the Weird: examining the aesthetic development of Weird Fiction from the late nineteenth to the early twenty-first centuries" explored the use of the sublime. grotesque, uncanny and abcanny in the Weird Fiction of H.P. Lovecraft and Chine Mieville. Ms Gadd was awarded first-class honours in Literature in 2014.

Abstract: "Weird Fiction" is identifiable by its atmosphere of cosmic fear and unease which is produced through the sublime and the grotesque. H. P. Lovecraft's "Weird Fiction" invokes the sublime through other-worldly creatures that inspire awe and terror; beyond the grasp of limited human consciousness, they are both unfathomable and unspeakable. Cosmic fear is further heightened in Lovecraft's fiction through transgressive meldings of 